\title{
Efectividad regulatoria de la responsabilidad social empresarial en Colombia*1
}

\section{Regulatory Effectiveness of corporate social liability in Colombia}

\author{
María Carolina Fajardo Cano ${ }^{2}$ \\ fajardo.maria@urosario.edu.co
}

\section{RESUMEN}

El panorama normativo actual de la responsabilidad social empresarial en Colombia resulta insuficiente, pues no permite alcanzar los beneficios que de la gestión empresarial espera una sociedad organizada. Este artículo tiene por objeto proponer un modelo de regulación distinto y único para Colombia, mediante el cual hacer efectivas las finalidades de la figura y obtener de esta el mayor provecho, analizada la experiencia nacional e internacional en la materia.

PALABRAS CLAVE: empresa, responsabilidad social empresarial, intervención estatal, libertad de empresa, función social empresarial, derecho comparado, cooperación público-privada.

Fecha de recepción: 2015/08/19

Fecha de evaluación: 2015/09/02

Fecha de aprobación: 2015/09/17

\section{ABSTRACT}

Colombia's current corporate social responsibility's regulatory landscape is insufficient as it cannot achieve the expectations that an organized society would have from corporate management. This article aims at thoroughly analyzing the matter from both, a national and international perspective, and then proposing a different and unique regulatory model for Colombia, that would fulfill such expectations and be most beneficial for society.

KEYWORDS: enterprise, corporate social responsibility, government intervention, entrepreneurial freedom, entrepreneurial social function, comparative law, publicprivate cooperation.

* Cómo citar este artículo: Fajardo Cano, M. C. (Diciembre, 2015). Efectividad regulatoria de la responsabilidad social empresarial en Colombia. Criterio Jurídico Garantista, 8(13), 130-155.

1. Artículo de reflexión, producto de la investigación dirigida por el profesor Mgr. Édgar Iván León Robayo, como trabajo de grado para optar por el título de magíster en Derecho Privado, del Colegio Mayor de Nuestra Señora del Rosario.

2. Abogada (2013); profesora auxiliar de la asignatura Derecho Civil, Personas y Familia; estudiante de la Maestría en Derecho Privado, del Colegio Mayor de Nuestra Señora del Rosario. 


\section{Introducción}

De tiempo atrás la empresa ha sido el eje central de la economía y la principal unidad de producción de riqueza. Inicialmente, sus deberes y obligaciones se habían circunscrito a alcanzar los objetivos propios de su creación. Con el paso del tiempo, diferentes fenómenos han dado lugar a que poco a poco deba entrar a considerar el impacto de su funcionamiento, asumiendo cargas y deberes que trascienden la órbita de sus actividades principales.

Así, el entorno en el cual las empresas desarrollan sus actividades ha llevado a que deban adaptarse a parámetros que les permitan un equilibrio entre los beneficios alcanzados y los obtenidos por los grupos de las áreas donde operan. Deben, entonces, trazar estrategias o planes de acción que van más allá de los objetivos puramente económicos, teniendo que entrar a actuar frente a determinadas situaciones, de la mano de otros agentes (Arroyo, 2012). Este es el escenario en el cual encuentra su razón de ser la responsabilidad social empresarial (RSE), figura a través de la cual han sido fijados los lineamientos y pautas de comportamiento a los que debe ajustarse el actuar de la empresa considerando su entorno, sus necesidades propias y las de los diferentes grupos sobre los cuales tienen incidencia sus operaciones.

Este tema ocupa un papel cada vez más preponderante en diferentes ámbitos tanto internacionales como nacionales, en los que las discusiones giran en torno al rol que debe jugar la empresa en el desarrollo social y ambiental, haciéndose evidente la necesidad de involucrar en ello a las compa- ñías de forma directa. Como resultado, se vienen creando diversos instrumentos a nivel normativo que legitiman la transferencia a las empresas de determinadas responsabilidades con las que no contaban en un principio.

A pesar de lo anterior, existen vacíos que llevan a cuestionarse acerca del alcance y efectividad de la RSE y a preguntarse hasta qué punto las disposiciones que rigen la materia resultan o no vinculantes para las compañías. El presente artículo busca proponer un modelo de regulación de la RSE en Colombia, en pro del cumplimiento de los objetivos de la figura y de cómo obtener de esta el mayor provecho.

Para ello, se realizó un análisis desde el derecho tanto interno como comparado, en atención a los disímiles tratamientos que la RSE puede llegar a recibir en los diferentes ordenamientos jurídicos. Ante la escasez de información sobre algunos elementos, tales como el alcance del concepto y el desarrollo de la figura en sí misma, se acudió a lo que al respecto se ha estudiado desde las ciencias económicas, lo cual sirvió de sustento para una comprensión a fondo de esta y facilitó el estudio de su tratamiento en el orden jurídico.

La investigación se adelantó haciendo un seguimiento a las novedades del tema en el campo jurídico, nutrido con diferentes fuentes: artículos académicos, bibliografía especializada, noticias, entrevistas a empresarios cuyas compañías trabajan actualmente en la implementación o fortalecimiento de programas de RSE, proyectos de ley que tocan el tema de forma indirecta y entrevistas con funcionarios que por vía de dichos proyectos fomentan la aplicación de la figura como herra- 
mienta que incentive a las compañías a adelantar programas de responsabilidad social.

Como resultado de lo anterior, el artículo se ha dividido en cinco partes principales: partiendo del estudio del concepto de la RSE y los ámbitos que esta abarca, en la segunda y tercera parte se presenta el tratamiento que se le ha dado a la figura tanto en el derecho comparado como dentro del ordenamiento jurídico interno, respectivamente, para en la cuarta parte formular la propuesta respecto a la forma en que podría ser manejada la RSE en Colombia de modo tal que resulte vinculante y se maximicen sus beneficios, y finalmente la conclusión.

\section{Responsabilidad social empresarial: con- cepto y generalidades}

\section{Definición}

A pesar de la importancia que el tema ha venido cobrando con el paso del tiempo y el lugar preponderante que ha llegado a ocupar, en la actualidad no existe un concepto unificado acerca de lo que debe entenderse por RSE. Es posible encontrar en la doctrina diferentes definiciones sin un consenso al respecto, así como tampoco sobre su alcance ni cuándo puede considerarse que una empresa es socialmente responsable o no (Crespo, 2010).

La principal discusión gira en torno al carácter obligatorio o voluntario de la figura, puesto que gran parte de la doctrina y muchos organismos de orden nacional e internacional han incluido dicho aspecto como un componente de su definición (Crane, McWilliams, Matten, Moon y Siegel, 2009). Esta forma de entenderla fue establecida desde hace varias décadas y tomó fuerza no solo en la doctrina sino, incluso, en el seno de organismos o instituciones para los cuales la RSE se ha convertido en un tema de especial ocupación. ${ }^{3}$ A pesar de ello, la dinámica del mercado y la evolución de la figura llevan a que este aspecto pueda ser dejado de lado como un elemento propio de la definición de RSE, en atención a que esta podría recibir un tratamiento de obligatoriedad o dejarse librada a la voluntad de las empresas, sin que en ninguno de los dos casos se pierda su esencia. ${ }^{4}$

Es posible tomar en cuenta, entonces, elementos comunes a numerosas definiciones de RSE con las que se cuenta en la actualidad y que podrían considerarse esenciales, logrando con ello que pueda

3. Por ejemplo, la Comisión de las Comunidades Europeas ha definido en su Libro Verde a la RSE como "la integración voluntaria por parte de las empresas, de las preocupaciones sociales y medioambientales en sus operaciones comerciales y en sus relaciones con sus interlocutores" (2001, pág. 7). En Colombia, por su parte, la Guía técnica colombiana 180 de responsabilidad social la define como "el compromiso voluntario que las organizaciones asumen frente a las expectativas concertadas que en materia de desarrollo humano integral se generan con las partes interesadas” (Icontec, 2008, pág. 7).

4. Esta forma de definir la RSE desde lo voluntario o lo obligatorio ha sido vista como inconveniente por algunos autores como Gjølberg, para quien: "las definiciones más actuales de RSE enfatizan la naturaleza voluntaria de la RSE (...) esto no puede servir como definición debido al simple hecho de que los marcos legales relevantes difieren (...) una acción clasificada como iniciativa de RSE voluntaria en otro país cae a la categoría de cumplimiento normativo dentro de otra” (2009, págs. 21-22).

Criterio Jurídico Garantista. (Jul.-Dic. de 2015). Vol. 8, n. ${ }^{\circ}$ 13, 130-155. ISSN: 2145-3381. Bogotá: Universidad Autónoma de Colombia. 
ser entendida en un sentido amplio y responda a las diferentes realidades actuales. En este entendido, la RSE puede definirse, en términos generales, como la realización de acciones por parte de la empresa, dentro de una actitud comprometida con los sujetos frente a los que tiene incidencia su actuar — grupos de interés (stakeholders) — tanto al interior como al exterior de la compañía, teniendo en cuenta para la toma de decisiones e implementación de estrategias de funcionamiento el impacto que generan sus operaciones en campos como el económico, social, laboral, ambiental, entre otros (Crane et al., 2009; Alanis, Tello y Sánchez, 2013).

\section{Objetivos y campos de acción}

La doctrina se ha pronunciado acerca de los objetivos o fines de la RSE en lo que ha denominado búsqueda del triple beneficio (triple bottom

\begin{tabular}{|c|}
\hline La función social de \\
la empresa, también \\
contemplada en el artículo \\
333 de la Constitución \\
Política, encuentra su \\
fundamento en el rol \\
que los individuos tienen \\
dentro de su comunidad y \\
se convierte en la principal \\
razón por la cual es posible \\
entender a una compañía \\
desde dos dimensiones: la \\
de las libertades y derechos \\
que le son conferidos y la \\
de las responsabilidades \\
correlativas a estos. \\
\hline
\end{tabular}

económicos, medioambientales y relativos a la lucha contra la corrupción, entre otros (Acevedo, Zárate y Garzón, 2013).

Se persigue también la concientización de las compañías en cuanto a las consecuencias de su funcionamiento, la importancia de adelantar acciones que aminoren sus efectos negativos, la maximización de sus beneficios yendo más allá de las metas u objetivos puramente económicos y la cooperación con el Estado para que, a través de un trabajo mancomunado, puedan alcanzarse objetivos de satisfacción de necesidades de la población (Núñez, 2011).

\section{Antecedentes históricos y evolución}

La doctrina ha coincidido de forma mayoritaria en afirmar que fue hacia mediados del line), que implica: perseguir rentabilidad a nivel económico, maximización del bienestar social y preservación del medio ambiente- (Ibarra, 2014). Así, el objetivo primordial de la RSE es lograr que las actividades de las compañías impacten positivamente el entorno dentro del cual realizan sus operaciones, y que estas traigan beneficios tanto para la empresa como para aquellos grupos con los cuales tiene relación — socios, trabajadores, clientes, grupos cercanos a la empresa-, al igual que ventajas para la comunidad y su desarrollo en ámbitos como derechos humanos, laborales, siglo XX cuando comenzó a surgir la idea de RSE, entendida de forma similar a lo que hoy se tiene por tal, por ser ese el momento en el cual empezaron a formularse las inquietudes acerca de los deberes que las empresas — que ocupaban ya para ese entonces una posición muy importante dentro de la comunidad—, debían asumir frente a sus situaciones problemáticas.

Pero es sobre todo en el siglo XXI cuando cobra real importancia al ocupar un lugar central en las decisiones adoptadas en el seno de organismos 
internacionales, para los que la RSE ha comenzado a convertirse en respuesta a situaciones problemáticas de diferentes comunidades alrededor del mundo. Así, este tema ha sido objeto de pronunciamiento por parte de importantes organismos como la Organización de las Naciones Unidas (ONU), la Organización Internacional del Trabajo (OIT), la Organización para la Cooperación y el Desarrollo Económicos (OCDE), diferentes organizaciones protectoras de derechos humanos, organizaciones no gubernamentales (ONG) y numerosos Estados alrededor del mundo.

Ahora bien, al indagar acerca de los orígenes o antecedentes de la RSE en Colombia, se encuentra que desde mediados del siglo XX se crearon por parte de las empresas figuras cuyo objetivo era brindar apoyo a la comunidad; estas tenían inicialmente un carácter voluntario pero con posterioridad se tornaron obligatorias por disposición del Gobierno nacional. ${ }^{5}$ Con el paso del tiempo el Gobierno empezó a crear incentivos para que las diferentes compañías adelantaran acciones benéficas en pro de la sociedad (Ibarra, 2014).

A lo anterior se suma, como antecedente de gran importancia en nuestro país, el establecimiento de principios y mandatos de orden constitucional como la solidaridad y la función social de la empresa, que se han convertido en pilares de la figura y han hecho que cuente con mayor importancia dentro del ordenamiento jurídico colombiano. ${ }^{6}$

\section{La responsabilidad social empresarial en el derecho comparado}

Fenómenos como la globalización, las dificultades sociales de la población en numerosos países, los escándalos por prácticas corporativas cuestionables, entre otros, han llamado la atención de la comunidad internacional y llevado a que como respuesta surjan diferentes instrumentos que establecen directrices para promover un tratamiento adecuado a la RSE en los diferentes Estados, encontrándose entre los más importantes los siguientes:

a) Global Compact o Pacto Global (ONU, 1999). Considerada actualmente como la iniciativa más importante del mundo en el campo de la RSE. ${ }^{7}$ Este instrumento busca que tanto las empresas como las organizaciones gubernamentales y no gubernamentales que lo acogen

5. Por ejemplo, según sostiene Ibarra (2014) "en 1954 se crea el subsidio familiar, encaminado a mejorar el bienestar de los trabajadores mediante la creación de Cajas de Compensación autónomas financiadas con aportes patronales liquidados sobre el valor de la nómina de la empresa. (....) La participación de las empresas era voluntaria (...) Dicha iniciativa fue acogida por el Estado colombiano y se tornó obligatoria en 1957” (pág. 33).

6. Estos se encuentran consagrados en los artículos 95 y 333 de la Constitución Política de Colombia de 1991, respectivamente.

7. Véase: https://www.unglobalcompact.org/what-is-gc/participants/search?utf8=\%E2\%9C\%93\&search $\% 5 \mathrm{Bkeywords} \% 5 \mathrm{D}=$ avi anca\&button=\&search\%5Bper_page $\% 5 \mathrm{D}=10 \&$ search\%5Bsort_field $\% 5 \mathrm{D}=\&$ search $\% 5$ Bsort_direction $\% 5 \mathrm{D}=$ asc Y http: $/ /$ pactoglobal-colombia.org/index.php/sobre-pacto-global/que-es-pacto-global.

Criterio Jurídico Garantista. (Jul.-Dic. de 2015). Vol. 8, n. ${ }^{\circ}$ 13, 130-155. ISSN: 2145-3381. Bogotá: Universidad Autónoma de Colombia. 
voluntariamente, ${ }^{8}$ se comprometan a adoptar en la ejecución de sus funciones y actividades los diez principios que rigen el Pacto, garantizándose condiciones adecuadas para la población en materia de derechos humanos, derechos laborales, mecanismos anticorrupción y medioambiente.

b) Declaración del Milenio (ONU, 2000). Destaca la importancia de trabajar con empresas responsables para lograr la reducción de la pobreza, la desnutrición, el analfabetismo, entre otros (Carrillo y Toca, 2014).

c) Líneas directrices de la OCDE para empresas multinacionales (OCDE, 2013). Establecen recomendaciones de los gobiernos dirigidas a empresas multinacionales para una conducta empresarial responsable dentro del contexto global; buscan guiar los comportamientos de las empresas para que a través de ellas se protejan y desarrollen las comunidades en lo que respecta a los derechos humanos, asuntos laborales, medioambientales, medidas anticorrupción, ciencia y tecnología. d) Declaración tripartita sobre las empresas multinacionales y la política social (OIT, 1977 y 2000): dirigida a empresas y gobiernos, quienes pueden acogerse voluntariamente a esta. Fomenta el respeto de la soberanía estatal y el apego a las normas, usos y políticas nacionales en el desarrollo de sus operaciones, y promueve la ratificación y aplicación de las recomendaciones y convenios de la OIT.

e) Norma ISO 26000 Guía sobre responsabilidad social: sirve a las empresas para alcanzar el desarrollo sostenible, comportándose de modo socialmente responsable. Este instrumento se centra en el fomento de garantías a los derechos humanos, laborales y medioambientales, así como en temas relativos a prácticas justas de mercado, respeto y protección del consumidor, en aras de alcanzar el progreso social (Acevedo et al., 2013).

Adicionalmente a la emisión de los anteriores instrumentos internacionales, ${ }^{9}$ las empresas del mundo entero han empezado a adoptar programas de RSE. La forma en que ello se presenta

8. Una de las principales críticas que recibe este Pacto es precisamente que, al ser de voluntaria adhesión, no cuenta con medios para exigir coactivamente su cumplimiento y, por tanto, no se puede garantizar su efectividad. Únicamente se entiende como obligatorio para quienes se acogen a este, la presentación de un informe de progreso que es rendido anualmente por parte de los adscritos al Pacto (Acevedo et al., 2013).

9. Los instrumentos relacionados anteriormente son los que han tenido mayor acogida a nivel mundial. Sin embargo, cabe destacar también la importancia de pronunciamientos sobre la materia proferidos por otras instituciones. Por ejemplo, recientemente la Iglesia Católica en la Carta Encíclica Laudatio Si se ha pronunciado frente al tema (S. S. Francisco, 2015), reiterando puntos sobre los cuales había llamado la atención previamente a las empresas —Carta apostólica Octogesima adveniens (1971); Acta Apostolicae Sedis - AAS 63 (1971), págs. 416-417; Carta Encíclica Centesimus annus (1991); Acta Apostolicae Sedis - AAS 83 (1991), pág. 863-, exhortándolas a cumplir con la RSE debida en campos como el medioambiente y la satisfacción de necesidades de la sociedad.

Criterio Jurídico Garantista. (Jul.-Dic. de 2015). Vol. 8, n. ${ }^{\circ}$ 13, 130-155. ISSN: 2145-3381. Bogotá: Universidad Autónoma de Colombia. 
depende del ordenamiento jurídico de los países en los cuales opera cada compañía y del panorama económico, cultural y social propio de cada uno de estos Estados (Gjølberg, 2009). A continuación se expone el panorama que presenta la figura en algunos países:

a) Estados Unidos: allí un gran número de empresas cuenta con programas de RSE que se caracterizan por ser altamente publicitados por las propias compañías. No los llevan a cabo por el hecho de que se les obligue a través de normas federales, sino de manera voluntaria motivadas por incentivos que les generan grandes beneficios (Cecil, 2008). Tanto el Gobierno estadounidense ${ }^{10}$ como organizaciones de la sociedad civil ${ }^{11}$ han establecido autoridades encargadas de promover la RSE y guiar a las empresas en lo que requieran frente a esta materia.

b) En Latinoamérica es evidente que en los últimos años las compañías le dan cada vez más importancia al tema y empiezan a adoptar poco a poco programas de RSE. En países como México, Argentina, Perú, Brasil y Venezuela han sido creadas diferentes entidades y organizaciones dedicadas a su promoción. ${ }^{12}$ Así mismo, la cooperación entre países latinoamericanos ha llevado a que a escala regional hayan sido establecidas algunas organizaciones con el mismo fin. ${ }^{13}$

c) En la Unión Europea se destaca la adopción de diferentes medidas de RSE y el consecuente aumento de la cantidad de empresas que, siguiéndolas, establecen estrategias para aplicarlas dentro de sus programas de funcionamiento.

En ese marco fue emitido el Libro verde (Green Paper), instrumento de mayor importancia en esa región sobre la materia, que tiene por objeto fomentar la responsabilidad social de las empresas a nivel europeo e internacional (Comisión de las Comunidades Europeas, 2001).

Recientemente, el Parlamento y el Consejo Europeo adoptaron una Directiva por medio

10. Por ejemplo, al interior de la Oficina de Relaciones Económicas y Empresariales se ha establecido un equipo que trabaja en conjunto con otras agencias y departamentos para lograr objetivos de divulgación y fomento de las acciones empresariales socialmente responsables. Ver: http://www.state.gov/e/eb/eppd/csr/

11. Como un ejemplo, ver: US Corporate Responsibility: www.uscorporateresponsibility.org

12. En Brasil, por ejemplo, se creó el Instituto ETHOS, al que se encuentran afiliadas más de 800 empresas. En México existe la organización AliaRSE, cuya coordinación se encuentra a cargo de la Corporación Mexicana de Empresarios. Argentina cuenta con el Instituto Argentino de Responsabilidad Empresarial creado en el año 2002, y en Perú fue creada en 1994 la organización Perú 2021 que tiene entre sus principales objetivos la promoción y gestión de acciones de RSE. En Venezuela, aun cuando no exista una ley específica sobre RSE que entre a regular el tema, sí han sido emitidas numerosas normas dispersas que obligan a las empresas a adelantar acciones sociales en diferentes campos, so pena de ser sancionadas. Se afirma que se ha dificultado la comprensión del alcance de la figura o de la legitimidad de dichas obligaciones que les son impuestas.

13. Al respecto pueden mencionarse la Red Interamericana de Fundaciones y Acciones Empresariales para el Desarrollo de Base de América-RedEAmérica- (www.redeamerica.org) y ForumAmérica (www.empresa.org).

Criterio Jurídico Garantista. (Jul.-Dic. de 2015). Vol. 8, n. ${ }^{\circ}$ 13, 130-155. ISSN: 2145-3381. Bogotá: Universidad Autónoma de Colombia. 
de la cual establecen la obligación para las empresas de emitir un informe anual, en el que se ponga en conocimiento de los grupos de interés el impacto de sus operaciones en los campos de derechos humanos, medioambiente y frente a la sociedad en general (European Comission for Corporate Justice, 2006).

d) En el Reino Unido, desde 1980 fueron creados sistemas que tenían como criterio de inversión el desempeño ético y social de las compañías (Ioannis y Serafeim, 2014). Con el tiempo, también se han establecido exigencias para las empresas desde el ámbito normativo, con las que se les imponen deberes de creación de estrategias de inversión social, ${ }^{14}$ y cuentan con organismos tanto gubernamentales como no gubernamentales que centran su funcionamiento en temas de RSE. ${ }^{15}$

e) India emitió el 30 de agosto de 2013 la Ley de las Empresas, en cuyo artículo 135 establece que las compañías que superen determinado tope de ingresos tienen la obligación de destinar un porcentaje de sus ganancias a adelantar acciones socialmente responsables, dentro de campos específicos definidos por el legislador. ${ }^{16}$

Así mismo, debe crearse un Comité de RSE al interior de cada empresa para asesorar a la junta directiva en los temas relativos a la materia y hacer un seguimiento a las sumas de dinero que se destinen a ello. Sus actividades deberán reportarse anualmente, detallando aquellas relativas a RSE que hayan sido adelantadas por la compañía, so pena de que esta o sus directivos sean sancionados con altas multas (Kordant Philanthropy Advisors, 2013).

f) Por último, se trae a colación el caso de Indonesia donde la RSE ha sido un tema al que el Gobierno de ese país ha prestado atención desde 1989, cuando se establecieron programas de apoyo a la comunidad por parte de las empresas de propiedad del Estado. Posteriormente, con la expedición de la Ley 40/2007, ${ }^{17}$ se establece la obligatoriedad de adelantar acciones de RSE para empresas que se dediquen a explotar recursos naturales. Dispone la fijación de parámetros para los programas de

14. Por ejemplo, desde julio de 2000, la ley británica Trustee Act exige que todos los administradores de fondos de pensiones comuniquen su política en materia de inversión socialmente responsable.

15. Se destaca el establecimiento del Minister for Corporate Social Responsibility, destinado exclusivamente a asuntos de RSE, que trabaja en conjunto con un cuerpo interministerial con el objetivo de apoyar la promoción y fomento de esta desde el Gobierno. En el año 2000 se creó el UK Social Investment Taskforce, grupo que tiene como objetivo identificar los obstáculos a la inversión socialmente responsable y a darles solución. Existe también la Corporate Responsibility Coalition (CORE), coalición de la que hacen parte más de 130 organizaciones y representantes tanto del Gobierno como de la sociedad civil (www.corporate-responsibility.org).

16. Se calcula que esta medida opera frente a más de 2500 compañías en India y que puede generar inversión de más de 2 billones de dólares en la comunidad a través de proyectos de RSE (Estudio de Ernst \& Young, citado por Kordant Philanthropy Advisors, 2013).

17. Disponible en: http://irmadevita.com/wp-content/uploads/2008/04/company-law-uu-40-2007.pdf 
RSE, principios rectores, así como incentivos y sanciones, por medio de regulación complementaria (Gayo, 2012).

$\mathrm{El}$ anterior panorama permite evidenciar que en los últimos años la RSE es un tema de especial ocupación en diferentes escenarios mundiales. Existe una tendencia actual a que los Estados intervengan a través de regulación de la RSE en sus ordenamientos jurídicos, bien sea en su totalidad o en determinados campos. Se busca, pues, dotarla de cierto carácter vinculante para poder exigir a las empresas el cumplimiento de las disposiciones normativas frente a la materia. Así mismo, se presenta a escala internacional cierto acompañamiento a las empresas por parte de autoridades del Gobierno, que facilita cumplir con los fines propios de la RSE, a través del trabajo conjunto Estado-sector empresarial.

\section{La responsabilidad social empresarial en Colombia}

\section{Principios rectores en el ordenamiento jurídico colombiano}

Las acciones de RSE de las empresas en Colombia se encuentran delimitadas por disposiciones jurídicas que establecen los parámetros a los que se deben circunscribir. Los principios más importantes que rigen la materia son la libertad de empresa y la función social de esta.
De tiempo atrás la libertad de empresa ha sido el pilar fundamental del actuar de las compañías, gracias al importante rol que esta juega como promotora de desarrollo en la sociedad. Dicho principio se desprende de lo establecido en el artículo 333 de la Constitución Política, y se encuentra bajo la dirección del Estado a quien corresponde tomar las medidas necesarias para garantizar su efectividad. ${ }^{18}$

La libertad de empresa ha sido entendida como la facultad de los ciudadanos para participar en la economía de la nación, según sus preferencias, a través de la realización de actividades económicas, con miras a obtener un beneficio. ${ }^{19}$ Se manifiesta en aspectos como la posibilidad de fundar la empresa, elegir la forma de dirigirla, organizarla y desarrollar la actividad en el mercado en la forma en que a bien se tenga. Con fundamento en este principio se les confiere a los particulares la potestad de definir el funcionamiento de las compañías conforme a sus intereses, dentro del marco de la autonomía privada de la voluntad (Sabogal, 2005).

Ahora bien, existen limitaciones a la libertad de empresa que se consagran de forma expresa en la Constitución Política (Correa, 2008), en aras de salvaguardar otros bienes jurídicos con los que podría entrar en colisión (Jaramillo, 2015). El bien común, los intereses colectivos, los derechos fundamentales, la preservación del medioambiente, el patrimonio cultural de la nación, entre otros,

18. La Corte Constitucional colombiana se ha pronunciado frente a estos puntos en las sentencias C-870/03, C-265/94, C-615/02, C-830/ 10 y C-882/14, entre otras.

19. Véanse: Corte Constitucional, sentencias T-425/92, C-615/02, C-830/10 y C-882/14; Corte Suprema de Justicia, sentencia del 28 de septiembre de 1938, M. P.: Eleuterio Serna R. Gaceta Judicial, Tomo XLVII, n. ${ }^{\circ}$ 1940, pág. 218 ,

Criterio Jurídico Garantista. (Jul.-Dic. de 2015). Vol. 8, n. ${ }^{\circ}$ 13, 130-155. ISSN: 2145-3381. Bogotá: Universidad Autónoma de Colombia. 
constituyen campos en los cuales la empresa no podrá interferir irrazonablemente, debiendo velar porque en sus operaciones se respeten plenamente. ${ }^{20}$ Cabe aclarar que las restricciones que imponga el Estado no pueden ser arbitrarias y deben contar, a su vez, con un límite. Lo anterior ha sido objeto de pronunciamiento de la Corte Constitucional, corporación que en reiteradas oportunidades ha establecido que no podrá violarse el núcleo esencial de la libertad de empresa ni su libre iniciativa. ${ }^{21}$

Por su parte, la función social de la empresa, también contemplada en el artículo 333 de la Constitución Política, ${ }^{22}$ encuentra su fundamento en el rol que los individuos tienen dentro de su comunidad ${ }^{23}$ y se convierte en la principal razón por la cual es posible entender a una compañía desde dos dimensiones: la de las libertades y derechos que le son conferidos y la de las responsabilidades correlativas a estos.
Se concluye, entonces, que existen dos grandes principios de orden constitucional que rigen la materia: la libertad de empresa y la función social. En virtud de ellos, cada compañía puede definir su forma de constitución y funcionamiento, en búsqueda de su propio crecimiento económico y del desarrollo de las comunidades frente a las cuales sus operaciones tienen incidencia. El Estado deberá velar por el cumplimiento de los objetivos sociales y ejercer un control sin vulnerar los derechos y fines propios de cada compañía (Zavala, 1971).

\section{Disposiciones legales relativas a las empresas}

Circunscritas al marco de los principios anteriormente expuestos se han establecido diferentes disposiciones en el ordenamiento jurídico colombiano, que serán estudiadas en dos grupos: el marco normativo que regula los comportamientos de la empresa de manera general y el marco normativo referido específicamente a la RSE.

20. El establecimiento de las anteriores restricciones encuentra su fundamento en la necesidad de que exista un adecuado equilibrio entre la libertad otorgada a las empresas y los demás intereses públicos y particulares garantizados en la Carta Política, encaminados a cumplir las finalidades propias del Estado social de derecho. Al respecto: Corte Constitucional, sentencias C-624/98, C-882/14, C-882/14, C-265/94, C-524/96, T-356/99, C-870/03, C-615/02, C-624/98 y Corte Suprema de Justicia, sentencia del 28 de septiembre de 1938, M. P.: Eleuterio Serna R. Gaceta Judicial, Tomo XLVII, n. ${ }^{\circ}$ 1940, pág. 218.

21. Existe un precedente consolidado en el sentido que la medida de intervención estatal en la economía solo resultará admisible cuando se cumplan los siguientes requisitos: “i) necesariamente debe llevarse a cabo por ministerio de la ley; ii) no puede afectar el núcleo esencial de la libertad de empresa; iii) debe obedecer a motivos adecuados y suficientes que justifiquen la limitación de la referida garantía; iv) debe obedecer al principio de solidaridad; y v) debe responder a criterios de razonabilidad y proporcionalidad." (CConst., C-392 de 2007, H. A. Sierra). Sobre el particular, véase también Corte Constitucional, sentencias C-615/02, C-882/14, C-830/10, T-291/94, C-830/10 y C-870/03.

22. El referido artículo dispone en su inciso 30: "La empresa, como base del desarrollo, tiene una función social que implica obligaciones. El Estado fortalecerá las organizaciones solidarias y estimulará el desarrollo empresarial” [cursivas fuera del texto original].

23. Este concepto de función social tiene su origen en los Estudios sobre la transformación del Estado de León Duguit, que sostenía: "Todo individuo tiene en la sociedad una cierta función que cumplir, una cierta tarea que ejecutar. Y ese es precisamente el fundamento de la regla de derecho que se impone a todos, grandes y pequeños, gobernantes y gobernados... Todo hombre tiene una función social que llenar, y por consecuencia tienen [ sic] el deber social de desempeñarla; tiene el deber de desenvolver, tan

Criterio Jurídico Garantista. (Jul.-Dic. de 2015). Vol. 8, n. ${ }^{\circ}$ 13, 130-155. ISSN: 2145-3381. Bogotá: Universidad Autónoma de Colombia. 
Marco normativo general de acción de la empresa

Las operaciones de las compañías permean diferentes campos, lo que ha llevado a "visualizar el fenómeno económico-social desde distintos observatorios: laboral, tributario, mercantil, administrativo, financiero, benéfico o de utilidad común, corporativo, penal, entre otros" (Narváez, Narváez y Narváez, 2008, pág. 19). Cada una de estas áreas del derecho busca garantizar que el actuar empresarial se ajuste a los principios rectores de la materia.
Así, temas como las condiciones de los trabajadores de las empresas, los derechos de sus consumidores o usuarios, la protección del entorno en el cual operan, las acciones que adelantan, entre otros aspectos, se han convertido en objeto de pronunciamiento del legislador colombiano. Puede, entonces, evidenciarse que existe un marco normativo que regula de manera general los deberes que deben asumir las empresas en Colombia, como se analiza en el cuadro 1.

Cuadro 1. Marco normativo de los deberes y parámetros de los comportamientos empresariales en Colombia

\begin{tabular}{|c|c|c|}
\hline ASPECTO TRATADO & $\begin{array}{c}\text { ÁREA DEL } \\
\text { ORDENAMIENTO } \\
\text { QUE LO CONSAGRA }\end{array}$ & DISPOSICIONES NORMATIVAS \\
\hline $\begin{array}{l}\text { DERECHOS } \\
\text { HUMANOS }\end{array}$ & $\begin{array}{c}\text { DERECHO } \\
\text { CONSTITUCIONAL } \\
\text { DERECHO CIVIL }^{24}\end{array}$ & $\begin{array}{l}\text { Art. } 93 \text { C. P.: tratados y convenios internacionales relativos } \\
\text { a DD. HH. Art. } 77-2 \text { C. P.: entes que protegen y aseguran } \\
\text { efectividad en DD. HH. Art. } 2356 \text { C. C.: imputación de daño } \\
\text { y reparación. }\end{array}$ \\
\hline $\begin{array}{l}\text { CONDICIONES DE } \\
\text { LOS TRABAJADORES }\end{array}$ & $\begin{array}{c}\text { DERECHO } \\
\text { CONSTITUCIONAL }\end{array}$ & $\begin{array}{l}\text { Artículo } 25 \text { C. P.: trabajo como derecho fundamental. } \\
\text { Arts. } 38 \text { y } 55 \text { C. P.: derecho de asociación, negociación colec- } \\
\text { tiva, sindicatos, etc. } \\
\text { Art. } 17 \text { C. P.: prohibición de esclavitud, servidumbre y trata } \\
\text { de personas. } \\
\text { Art. } 53 \text { C. P.: convenios internacionales del trabajo como } \\
\text { legislación interna. }\end{array}$ \\
\hline
\end{tabular}

completamente como le sea posible, su individualidad física, intelectual y moral para cumplir esa función de la mejor manera posible y nadie puede entorpecer ese libre desenvolvimiento." (CConst., T-002 de 1992, C. Angarita).

24. Se incluye esta área en consideración a lo expuesto por la doctrina referente a la existencia de figuras en este campo — como la responsabilidad por actividades peligrosas — que permiten garantizar la protección de los derechos humanos (Céspedes y Gutiérrez, 2012). 


\begin{tabular}{|c|c|c|}
\hline & $\begin{array}{l}\text { DERECHO } \\
\text { LABORAL }\end{array}$ & $\begin{array}{l}\text { Ley } 50 \text { de 1990: Código Sustantivo del Trabajo. } \\
\text { Ley } 100 \text { de 1993: Sistema de seguridad social integral. } \\
\text { Ley } 21 \text { de 1982: subsidio familiar. }\end{array}$ \\
\hline $\begin{array}{l}\text { PROTECCIÓN AL } \\
\text { MEDIO AMBIENTE }\end{array}$ & $\begin{array}{c}\text { DERECHO } \\
\text { CONSTITUCIONAL } \\
\text { DERECHO } \\
\text { AMBIENTAL y } \\
\text { ADMINISTRATIVO }\end{array}$ & $\begin{array}{l}\text { Decreto } 2811 \text { de 1974: Código Nacional de Recursos Na- } \\
\text { turales. } \\
\text { Ley } 99 \text { de 1993: Ministerio del Medio Ambiente. } \\
\text { Decreto } 2150 \text { de 1995: planes de manejo ambiental. }\end{array}$ \\
\hline $\begin{array}{l}\text { RELACIÓN CON } \\
\text { CONSUMIDORES } \\
\text { Y/O USUARIOS }\end{array}$ & $\begin{array}{c}\text { DERECHO } \\
\text { CONSTITUCIONAL } \\
\text { DERECHO } \\
\text { COMERCIAL y } \\
\text { ADMINISTRATIVO }\end{array}$ & $\begin{array}{l}\text { D. P.: art. 78: protección del consumidor; medidas de control } \\
\text { y garantías. } \\
\text { Ley } 1480 \text { de } 2011 \text { : Estatuto del Consumidor. } \\
\text { Decreto } 2153 \text { del } 30 \text { de diciembre de 1992: Superintendencia } \\
\text { de Industria y Comercio. } \\
\text { Decreto-Ley } 3163 \text { de 1968: Superintendencia de Sociedades. }\end{array}$ \\
\hline CORRUPCIÓN & $\begin{array}{l}\text { DERECHO } \\
\text { CONSTITUCIONAL } \\
\text { DERECHO } \\
\text { ADMINISTRATIVO }\end{array}$ & $\begin{array}{l}\text { B. P.: Contraloría, Procuraduría (título X - capítulos I y II). } \\
\text { Fiscalía General de la Nación (título VIII - capítulo Sexto). } \\
\text { Decreto } 1860 \text { de 1991: Moralización y eficiencia de la Ad- } \\
\text { ministración Pública. } \\
\text { Ley 1474 de } 2011 \text { : Nuevo Estatuto Anticorrupción. } \\
\text { Decreto } 2405 \text { de 1998: Lucha contra la corrupción. } \\
\text { Decreto-Ley } 3163 \text { de 1968: Creación de la Superintendencia } \\
\text { de Sociedades. } \\
\text { Ley } 599 \text { de } 2000: \text { Código Penal colombiano. }{ }^{26} \\
\text { Ley } 1121 \text { de 2006: Terrorismo y otras disposiciones. }\end{array}$ \\
\hline
\end{tabular}

25. Cabe traer a colación el hecho de que hoy en día, el Gobierno nacional ha tratado de fortalecer la normatividad en este campo, imponiendo sanciones administrativas a empresas cuyas acciones no se ajustan a la ley. Por ejemplo, actualmente hace trámite en el Congreso de la República un proyecto de ley mediante el cual se "dictan normas sobre la responsabilidad de las personas jurídicas por actos de corrupción transnacional”, en el cual vale la pena llamar la atención sobre los artículos 7 y 20 en los que se contempla la posibilidad de tener en cuenta la implementación previa por parte de la empresa de programas de transparencia y ética empresarial, a la hora de graduar la pena a imponer. Esto abre las puertas al hecho de que en un futuro la RSE pueda convertirse en una forma de atenuar penalidades a empresas sancionadas o incluso podría llegar a pensarse en convertirla en un mecanismo opcional a través del cual estas puedan cumplir parte de las sanciones impuestas, a modo de redención de penas.

26. Podrían mencionarse tipos penales como el lavado de activos (art. 323), el enriquecimiento ilícito de particulares (art. 327), la utilización indebida de fondos captados del público (art. 314), las operaciones no autorizadas con accionistas o asociados (art. $315)$, la omisión de agente recaudador (art. 402) y el soborno transnacional (art. 433), entre otros.

Criterio Jurídico Garantista. (Jul.-Dic. de 2015). Vol. 8, n. ${ }^{\circ}$ 13, 130-155. ISSN: 2145-3381. Bogotá: Universidad Autónoma de Colombia. 
Marco normativo propio de la responsabilidad social empresarial

Se encuentran muy pocas referencias específicas en el ordenamiento jurídico colombiano frente a la RSE. Son limitados los campos en los que esta materia ha sido objeto de pronunciamiento. Lo que se expone a continuación evidencia el lugar que ocupa actualmente,

Existen normas que establecen incentivos fiscales para las empresas que realicen donaciones a entidades cuyo objeto social se relacione con programas de desarrollo social de interés general. Se ofrecen también deducciones a las empresas jurídicas que realicen donaciones al Instituto Colombiano de Bienestar Familiar y a las redes de bibliotecas del país. ${ }^{27}$ Hay normas que vienen a complementar lo anterior, fijando el alcance que tendrán dichas disposiciones en diferentes campos. ${ }^{28}$

No se cuenta con normas adicionales que regulen directamente el tema, resultando evidente la ausencia de reglamentación específica sobre la materia, la falta de autoridades que controlen las acciones desplegadas por las compañías dentro del marco de la RSE o los efectos que estas generen. Lo anterior lleva a que no sea posible garantizar que tales acciones cumplan con su real cometido ni que el otorgamiento de beneficios cobre pleno sentido. ${ }^{29}$

A pesar de la escasa regulación específica frente al tema, no pueden desconocerse los esfuerzos realizados algunos años atrás para establecer un marco regulatorio propio de RSE. Se sometieron a debate ante el Congreso sendos proyectos de ley que tenían como objetivo regular los aspectos más importantes de la RSE: el 153 de 2006, el 31 de 2007, el 058 de 2009 y el 70 de 2010. Estos cuatro intentos de regular el tema en Colombia fracasaron, bajo el argumento errado de que regular la materia implicaría invadir la esfera de voluntad de la empresa y que con ello se desnaturalizaría la figura. ${ }^{30}$

27. El artículo 125 del Estatuto Tributario, a través de sus diferentes numerales, establece los parámetros para que pueda hacerse efectiva la deducción al impuesto de renta con ocasión de las donaciones a las que hace referencia. Establece así los requisitos que deben cumplir los beneficiarios de las donaciones (art. 125-1), las modalidades de las donaciones (art. 125-2), los requisitos para reconocer la deducción (art. 125-3) y los requisitos de las deducciones por donaciones (art. 125-4).

28. Pueden mencionarse, a modo de ejemplo, la Ley 397 de 1997 que hace referencia a los incentivos por donaciones al campo cultural, o el Decreto 2076 de 1992 relativo a la promoción y ayuda en el campo de la investigación científica y tecnológica.

29. A pesar de que no exista una autoridad creada por el Gobierno nacional para tales efectos, cabe destacar el hecho de que el sector privado creara el Consejo Empresarial Colombiano para el Desarrollo Sostenible (Cecodes), que desde 1993 busca orientar al país en dicho sentido. Está conformado por 38 empresas y 4 gremios de las áreas más importantes de la economía colombiana. Cecodes orienta a las empresas para que desarrollen y pongan en marcha prácticas que les permitan mejorar continuamente y lograr un equilibrio entre sus objetivos económicos, sociales y ambientales, en armonía con el desarrollo sostenible de la sociedad colombiana. Para lograrlo divulga, articula y fortalece la temática de la sostenibilidad y la responsabilidad social en la gestión del sector empresarial colombiano. Frente a esta última — RSE - cuenta con un programa que informa sobre la materia y promueve el desarrollo de planes de trabajo al respecto (Cecodes, s. f.).

30. Así se evidencia en el texto de la ponencia negativa al proyecto de ley número 326 de 2008 Cámara, 031 de 2007 Senado. Disponible en: http://es.scribd.com/doc/1 1498948/Ponencia-Negativa-Proyecto-de-Ley-Sobre-Rse\#scribd

Criterio Jurídico Garantista. (Jul.-Dic. de 2015). Vol. 8, n. ${ }^{\circ}$ 13, 130-155. ISSN: 2145-3381. Bogotá: Universidad Autónoma de Colombia. 
Se evidencia así que el ordenamiento jurídico colombiano no se ha hecho cargo directamente de la regulación de la RSE, dejando su desarrollo a las compañías, en un escenario de autorregulación (Melo y Guerra, 2005). Así,

parece haberse olvidado la trascendencia del derecho y de los sistemas normativos para redirigir los procesos económicos; tampoco se tiene en cuenta que el tránsito de la autorregulación a la regulación legal es necesario para dotar a las relaciones empresariales de un adecuado grado de imperatividad que tan solo el derecho puede garantizar (Jaramillo, 2015, págs. XXIII y XXIV).

\section{La responsabilidad social empresarial en la ju- risprudencia colombiana}

La RSE tampoco ha sido tema central de pronunciamiento de las altas Cortes colombianas, excepto por lo mencionado en algunas oportunidades, como se observa en la línea jurisprudencial que se sintetiza en el cuadro 2.

Cuadro 2. Línea jurisprudencial de la RSE en Colombia

\begin{tabular}{|c|l|l|}
\hline Rad. Sentencia & $\begin{array}{l}\text { TEMA CENTRAL DEL } \\
\text { PRONUNCIAMIENTO }\end{array}$ & $\begin{array}{l}\text { ASPECTOS DE RESPONSABILIDAD SOCIAL } \\
\text { EMPRESARIAL TRATADOS }\end{array}$ \\
\hline T-247 de 2010 & $\begin{array}{l}\text { Igualdad de género y tra- } \\
\text { bajo en condiciones de dig- } \\
\text { nidad. }\end{array}$ & $\begin{array}{l}\text { Afirma que la RSE:-Responde a la necesidad de } \\
\text { que la empresa, sea partícipe del desarrollo y } \\
\text { bienestar de la sociedad. -Viene a complementar } \\
\text { y enriquecer el ánimo de lucro que constituye el } \\
\text { núcleo teleológico de la empresa. - Hace de la } \\
\text { actividad de la empresa un instrumento de mejora } \\
\text { social, protección al medio ambiente, respeto de } \\
\text { los derechos fundamentales y otros elementos de } \\
\text { construcción social. }\end{array}$ \\
\hline C-608 de 2010 & $\begin{array}{l}\text { Tratado de libre comercio } \\
\text { entre Canadá y Colombia. }\end{array}$ & $\begin{array}{l}\text { Incluir principios de RSE en un TLC ayuda al cum- } \\
\text { plimiento de la solidaridad, la dignificación del } \\
\text { trabajo, el respeto por el medio y por los derechos } \\
\text { humanos. }\end{array}$ \\
\hline C-915 de 2010 & $\begin{array}{l}\text { Acuerdo sobre medio am- } \\
\text { biente entre Canadá y Co- } \\
\text { lombia. }\end{array}$ & $\begin{array}{l}\text { Alentar prácticas voluntarias de RSE fortalece la } \\
\text { coherencia entre los objetivos económicos y so- } \\
\text { ciales, enmarcándose dentro de la función social } \\
\text { de la empresa. }\end{array}$ \\
\hline
\end{tabular}




\begin{tabular}{|l|l|l|}
\hline T-129 de 2011 & $\begin{array}{l}\text { Derechos de comunidades } \\
\text { indígenas y explotación de } \\
\text { recursos naturales en sus } \\
\text { territorios. }\end{array}$ & $\begin{array}{l}\text { Para ser socialmente responsable la iniciativa pri- } \\
\text { vada debe ir más allá del mero cumplimiento de la } \\
\text { obligación legal, buscando la retribución al medio, } \\
\text { al desarrollo de las comunidades y mitigar los im- } \\
\text { pactos negativos. }\end{array}$ \\
\hline T-781 de 2014 & $\begin{array}{l}\text { Derecho a la vivienda digna } \\
\text { en diligencia de desalo- } \\
\text { jo. }\end{array}$ & $\begin{array}{l}\text { RSE como forma de autorregulación que trasciende } \\
\text { el cumplimiento de las normas y promueve benefi- } \\
\text { cios sociales más allá de los intereses de la empresa } \\
\text { del estándar requerido por la ley. Prácticas relacio- } \\
\text { nadas con el principio de solidaridad; concreción } \\
\text { de deberes constitucionales de actores que pueden } \\
\text { influir en el desarrollo de derechos fundamentales. } \\
\text { El actor principal de la RSE es la empresa, pero el } \\
\text { compromiso social debe ser complementado con la } \\
\text { participación de grupos de interés, de la sociedad } \\
\text { civilmente organizada, del Estado, los sindicatos, } \\
\text { organizaciones con interés social, ONG, entre otros. }\end{array}$ \\
\hline
\end{tabular}

En el cuadro 2 se puede ver cómo la RSE ni ha sido tema central de los pronunciamientos jurisprudenciales ni se ha ahondado suficientemente en ella cuando se ha debido tratar el tema. Tampoco se cuenta con fallos que se pronuncien frente a la materia dentro de su ratio decidendi sino que ha sido tocado a modo de obiter dicta, de forma muy tangencial (Acevedo et al., 2013).

\section{Propuesta de tratamiento de la responsa- bilidad social empresarial en colombia}

\section{Necesidad de intervención estatal}

El tratamiento dado a la RSE en Colombia se ha prestado para que muchas empresas hagan un uso indebido de ella al autodenominarse "socialmente responsables" y beneficiarse de forma injustificada de sus ventajas, sin adelantar acciones que realmente generen provecho a la comunidad o abandonando proyectos sin continuidad o resultado alguno (Ibarra, 2014).

La falta de concientización acerca de la importancia de la RSE ha llevado a que, en muchos casos, las empresas se limiten a perseguir beneficios puramente económicos, sin adquirir un real compromiso frente al tema social; "cuando las empresas acceden a la RSE solo por razones pragmáticas (...) la RSE suele ser menos abarcativa y se concreta en iniciativas específicas, no siempre dentro de un marco de inversión social-ambiental coherente" (Arroyo, 2012, págs. 9 y 10). 
Este problemático panorama lleva a que sea necesaria la adopción de medidas tendientes a darle un tratamiento específico. Es el Estado el llamado a regular lo necesario para que la RSE ofrezca el máximo provecho para los sujetos involucrados. Existen diferentes formas a través de las cuales el Estado puede intervenir en el desarrollo de la figura, siguiendo lo expuesto por Kovaliov y Streimiiene (2008, págs. 558 y 559).

a) Ordenador o mandador: el Estado establece estándares mínimos legales de comportamiento para la operación de las empresas, es decir, regula normativamente las actividades y acciones de las compañías.

b) Facilitador: el Estado, a través de sus organismos del sector público, estimula y promueve la participación de los actores más importantes en la agenda de la RSE, desarrollando herramientas de gestión e incentivos para dichos actores.

c) Acompañante o socio: permite las alianzas entre agentes; así, las habilidades o facultades propias del sector público se unen con las del sector privado y la sociedad civil para solucionar problemas sociales y ambientales complejos.

d) Aprobador o ratificador: este rol se manifiesta, por ejemplo, en la expedición de certificaciones de que se han adelantado acciones socialmente responsables, o el reconocimiento a través de premios o menciones especiales a aquellas empresas que han establecido este tipo de programas en procura del interés general.

El Estado puede asumir uno o varios de estos roles, pues las líneas que los dividen son muy delgadas; ello dependerá de la forma como adelante su intervención en el campo de la RSE. En la presente propuesta el Estado asumirá todos los roles, según el aspecto frente al que se encuentre.

\section{Funcionamiento de la propuesta}

A diferencia de lo que ocurre en el panorama actual — escasez de regulación frente a la RSE_-, se propone fortalecer la figura con la intervención del Estado quien regulará sus aspectos más importantes, haciendo exigibles comportamientos determinados a las compañías frente a la sociedad. Lo anterior se ilustra, comparativamente, en el gráfico 1.

\section{Gráfico 1. Comparación de panoramas de la RSE en Colombia}

\section{Panorama actual}

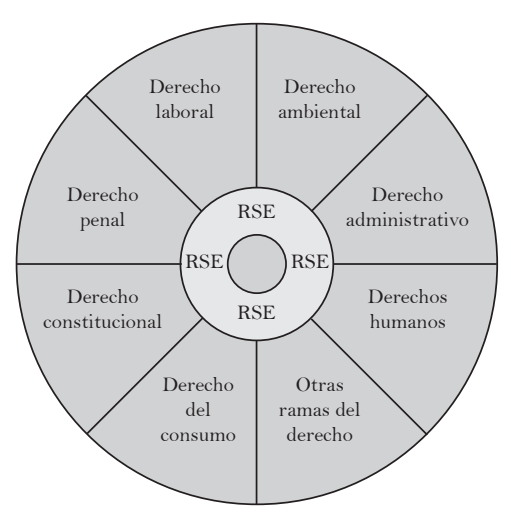

Propuesta - Panorama ideal

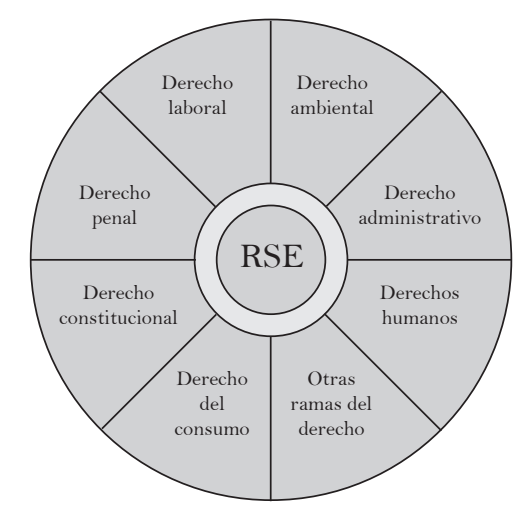

Obligatorio

Voluntario 
El gráfico muestra que en el campo de actividad de la empresa convergen tanto el marco jurídico general de acción de las compañías, que regulará los deberes básicos de estas a través de diferentes áreas del derecho como el campo regulatorio propio de la RSE.

Dentro de la propuesta que aquí se presenta las empresas deben cumplir obligatoriamente con deberes generales que establezcan los parámetros de comportamiento de todas las compañías. Así mismo, cada una de ellas tendrá la opción de decidir si, además, quiere ingresar de forma voluntaria al campo de regulación de la RSE; una vez en él, le serán impuestas obligaciones adicionales, relativas exclusivamente al desarrollo de acciones o programas de RSE. Existirá un control sobre

las actividades que adelanten en ese marco y les serán otorgadas ventajas de las que solo podrán beneficiarse las empresas que cumplan a cabalidad con lo regulado dentro de ese escenario.

A continuación se explicará el tratamiento propuesto frente a la RSE, atendiendo también a la división entre el marco de regulación general de acción de la empresa y el marco normativo específico de la figura.

\section{Marco normativo general de acción de la em- presa}

Lo dispuesto por el legislador en este ámbito deberá ser cumplido por todas las empresas, sin excepción, es decir, tanto por las que decidan ingresar al campo de la RSE como por aquellas que no lo hagan. Para propender por el fortalecimiento de este campo es necesario que existan normas que al regular el comportamiento general de las empresas garanticen no solo que sus operaciones respetan los derechos de los grupos de interés - evitando vulneraciones en el curso de sus operaciones-, sino que también ayuden a garantizar los fines de generación de riqueza que son esenciales de la empresa.

La imposición de obligaciones en este marco no debe llevar a transferir a las compañías las obligaciones que residen en cabeza del Estado y cuyo cumplimiento no les correspondería en principio. Esto supondría arriesgar el desarrollo adecuado de la empresa y se violarían principios como la libertad empresarial. Ahora bien, ello no obsta para que, si las compañías así lo deciden, pueda existir cooperación del sector empresarial con el Estado para el cumplimiento de dichos deberes, pudiendo trabajar conjuntamente por alcanzar esos fines en beneficio mutuo.

Actualmente existe la tendencia a excederse en la expedición de normas en este ámbito general dejando de lado la regulación específica de los temas relativos a la RSE, lo cual conduce a que las empresas se vean obligadas a destinar sus esfuerzos, herramientas y recursos al cumplimiento de esas obligaciones generales y vean disminuida la posibilidad de destinarlos a la realización de acciones socialmente responsables que beneficien en mayor medida a sus grupos de interés.

Es posible afirmar, entonces, que se presenta aquí un efecto inversamente proporcional: a mayor imposición de cargas legales en el ámbito normativo general de acción de la empresa, menor posibilidad de ejecución de acciones socialmente responsables por parte de las compañías. Esto 
lleva a que el campo de la RSE se vea "asfixiado" por la "sobre-expedición” de normatividad general (Matten y Moon, 2008).

\section{Ámbito específico de la responsabilidad social em- presarial}

En el marco de esta propuesta las compañías pueden optar por adelantar acciones en beneficio de sus grupos de interés, dentro de un ámbito que contará con una regulación específica propia. Una vez decidan acogerse a lo dispuesto sobre la materia por el legislador o por las autoridades que este cree o designe, se verán obligadas también al cumplimiento de las normas que rigen este campo. Tal regulación deberá estar definida previamente con absoluta claridad, de modo que no genere duda alguna a las empresas acerca del campo al cual ingresan, de las obligaciones que adquieren y de los beneficios a los que tienen derecho con ello. La legislación en esta materia deberá establecer:

a) Fomento y divulgación de la RSE: se deben dar a conocer por parte del Gobierno los medios a través de los cuales será posible acceder al campo de la RSE y las implicaciones que de ello se derivan. Se requiere también trabajar en la creación y actualización de estándares que se adapten a las realidades de las diferentes empresas que operan en el país, haciendo viable la creación de programas de RSE que se ajusten de la mejor manera a sus condiciones propias.

b) Parámetros que permitan tener claridad acerca de quién puede ser considerado socialmente responsable: para ello el Estado fijará unos requisitos mínimos y creará autoridades que tengan a su cargo verificar qué compañías cumplen con dichas exigencias adecuadamente y cuáles no.

c) Creación de incentivos y beneficios: el Estado debe fortalecer los escasos beneficios que existen en la actualidad y regularlos en mayor medida, para lograr que estos tengan un mayor alcance. Es preciso crear y reglamentar también otros beneficios que lleven a que la figura resulte atractiva para las empresas que implementen programas de RSE. ${ }^{31}$

d) Control: es necesario que exista control de las actividades que las empresas desarrollan en el marco de la RSE. Debe ejercerse vigilancia sobre la ejecución efectiva de los programas adelantados y verificar que tengan una adecuada continuidad que permita obtener los resultados esperados. Por esta vía se logrará también un control y supervisión frente a los beneficios que se generan con ocasión de la RSE, garantizando que estos sean otorgados únicamente a aquellas empresas que realmente los merecen por cumplir a cabalidad con todas las exigencias establecidas para acceder a ellos.

31. Es posible pensar, por ejemplo, a) en la inclusión del "componente social como criterio de elegibilidad de proveedores y contratistas del Estado” (González y Mayz, 2008, pág. 37), b) en el otorgamiento de etiquetas distintivas de las empresas socialmente responsables, lo cual les daría reconocimiento a nivel nacional e internacional, c) en divulgar por parte del Estado las acciones socialmente responsables que adelanten las compañías, con el fin de que la comunidad conozca y apoye a dichas empresas, y estas se vean beneficiadas a través del fortalecimiento de su nombre o reputación.

Criterio Jurídico Garantista. (Jul.-Dic. de 2015). Vol. 8, n. ${ }^{\circ}$ 13, 130-155. ISSN: 2145-3381. Bogotá: Universidad Autónoma de Colombia. 
Se contempla la posibilidad de imposición de sanciones a las empresas que no cumplan con las obligaciones adquiridas en el marco de la RSE, las cuales serán determinadas por el legislador o por las autoridades competentes para conocer de estos casos.

e) Guía y asesoría: implica brindar la capacitación necesaria en la materia y un acompañamiento permanente por parte del Estado tanto a las empresas que van a ingresar al campo de la RSE como a aquellas que ya estén ejecutando sus proyectos. Las compañías deben poder acudir a las autoridades estatales dedicadas al tema con fines consultivos y recibir la asesoría y el apoyo necesarios para poder ejecutar sus proyectos de RSE.

\section{Adaptación al ordenamiento jurídico colombiano}

Se está frente a una propuesta que responde tanto a los principios del ordenamiento jurídico colombiano como a las exigencias del mundo actual, lo que resulta ideal porque combina elementos voluntarios y coercitivos que dotan de exigibilidad a la figura sin invadir las esferas de autonomía y libertad de la empresa que el ordenamiento jurídico colombiano ha buscado proteger.

Darle a esta figura el tratamiento propuesto permitiría cambiar el panorama actual, en el que se dejan completamente librados a la voluntad de la empresa la forma, continuidad y resultados de la ejecución de programas de RSE. Se pasaría así a un escenario en el que se aplicaría una regulación específica que implica derechos y obligaciones para la empresa que decide acogerse a ella. Todas las disposiciones que se establezcan en la materia deberán ser cumplidas a cabalidad, so pena de asumir las consecuencias que se establezcan frente a su incumplimiento o infracción.

Se puede ver que principios como la libertad de la empresa son respetados plenamente, pues la toma de la decisión de ingreso o no al campo de la RSE permanece en cabeza de las compañías. La diferencia radica en el hecho que, una vez se ingrese en dicho escenario, el Estado intervendrá a través del establecimiento de obligaciones, ejercicio de control, otorgamiento de beneficios, acompañamiento, entre otros, permitiendo que la figura funcione de mejor manera y se obtenga de ella todo el provecho que actualmente no se logra por carecer de la exigibilidad necesaria.

Esta combinación de elementos voluntarios y regulación obligatoria ha sido ampliamente defendida en diferentes oportunidades y escenarios, al considerarse que cuando las medidas voluntarias resultan insuficientes las obligatorias entran a complementarlas adecuadamente y a dotarlas de herramientas para su correcto funcionamiento. Bajo esa óptica se ha sostenido que "se necesitan medidas reguladoras para complementar las iniciativas voluntarias en materia de $\operatorname{RSE}(\ldots)$ estas son solamente creíbles si se ponen en marcha garantías jurídicas eficaces." (European Commission for Corporate Justice, 2006, págs. 3 y 4).

La función social de la empresa, por su parte, se ve también enriquecida con esta propuesta porque le permite a las compañías ampliar el marco de beneficios que brindan a la sociedad. A su vez, la comunidad se verá beneficiada en mayor medida no solo con la generación de riqueza y el desa- 
rrollo que aporte la empresa a la sociedad por su simple funcionamiento, sino que obtendrá ventajas directas de los programas de RSE que estas adelanten. Lo anterior, teniendo en cuenta que las acciones que se implementen como parte de estos programas se encaminarán específicamente a mejorar las condiciones sociales, laborales, económicas y ambientales de los grupos de los cuales se rodean o frente a los cuales sus operaciones tienen incidencia.

\section{Beneficios de la propuesta}

Tal como se ha expuesto, la propuesta propende por la intervención estatal en la definición de los parámetros y manejo de los programas de RSE en Colombia. Así mismo, permite crear conciencia sobre la importancia de la figura, de su alcance y de los beneficios que trae a la sociedad, los cuales son subvalorados en nuestro país actualmente al no dársele el tratamiento adecuado. Bajo este entendido, la RSE se convertiría en una herramienta de gran utilidad para todos los sujetos involucrados:

a) Para el Estado este tratamiento de la RSE resulta benéfico pues le permite cumplir con sus deberes de garantía de derechos a la sociedad a través de la cooperación del sector empresarial. Al contar las compañías con medios y recursos significativos que facilitan la consecución de los objetivos propios del Estado social de derecho, estas serían de gran ayuda al Estado para cumplir con sus deberes de satisfacción de las necesidades de la población.

b) Para la empresa porque se generan grandes ventajas al obtener una mejora de sus resulta- dos económicos y mayor crecimiento en este campo. En el seno de organismos internacionales se ha venido hablando de los efectos directos e indirectos que genera la RSE para las compañías. Se afirma que como efecto directo, por ejemplo, ayuda a crear un

mejor entorno de trabajo que genera un mayor compromiso de los trabajadores e incrementa su productividad (...) Además, se logran efectos indirectos a través del aumento de la atención que prestan a la empresa consumidores e inversores, que ampliará sus posibilidades en el mercado. (Comisión de las Comunidades Europeas, 2001, pág. 8).

De manera adicional, deben tenerse en consideración los beneficios que le serían otorgados a la empresa por parte del Gobierno nacional en diferentes campos y que pueden llegar a constituir los móviles por los cuales estas deciden acogerse a la regulación de la RSE y adoptar programas en este sentido.

c) Para la sociedad porque se convierte en receptora de ventajas en la medida en que es a esta a la que se dirigen las acciones que adelantan las empresas. Así, tanto los grupos de interés como la sociedad civil, en términos generales, contarán con mayor garantía de protección de sus derechos, así como de satisfacción de sus necesidades básicas y las de su entorno.

Lo anterior evidencia cómo un adecuado tratamiento de la RSE puede tener grandes ventajas, una de ellas, garantizar los derechos de los grupos de interés y la sociedad en su conjunto, a través del trabajo mancomunado Estado-sector empresarial, cuya cooperación facilita alcanzar los objetivos de cada uno de estos. 


\section{Conclusión}

La empresa ocupa un destacado lugar en la sociedad en atención al importante rol que juega en la economía. Esto conlleva que deba prestarse mayor atención al ejercicio de sus actividades y a la forma como se relaciona con los sujetos frente a los cuales sus operaciones tienen incidencia. Con ocasión de lo anterior se han creado figuras que permiten establecer parámetros relativos a la forma en que se presenta dicha interacción, encontrándose la RSE entre las más importantes.

A través de esta figura las empresas adelantan acciones encaminadas a beneficiar a los diferentes grupos de interés involucrados en sus actividades.

De esta forma, entra a tenerse en consideración el impacto causado por su funcionamiento en los ámbitos económico, social, laboral, ambiental, entre otros. Se busca así maximizar el bienestar social, preservar el medio ambiente y generar rentabilidad a nivel económico, por medio de la cooperación de las empresas con el Estado para satisfacer las necesidades propias del entorno que las rodea.

Durante los últimos años se han venido adelantando acciones tendientes a fortalecer esta figura y se le ha venido dando mayor cabida en diferentes escenarios. No obstante, existen vacíos que llevan a cuestionarse acerca de su alcance y efectividad, al no haber total claridad acerca de qué tan vinculantes resultan las disposiciones relativas a la RSE para las compañías. Para comprender lo anterior es necesario efectuar un análisis del estado actual del tema tanto en el derecho comparado como en el ordenamiento jurídico interno.
El estudio del tratamiento dado a la RSE en diferentes países del mundo hace posible concluir que en el orden internacional existe una tendencia encaminada a incluir disposiciones específicas propias sobre la materia dentro del ordenamiento jurídico de diferentes Estados. Se ha entrado así a establecer mecanismos por medio de los cuales se les hace exigible a las compañías adelantar acciones socialmente responsables, siendo las autoridades estatales las encargadas de velar por el cumplimiento de las normas que regulan la materia. Ello ha traído consigo un fortalecimiento de la figura y la ha venido dotando, a escala internacional, de mayor fuerza vinculante y exigibilidad.

Por el contrario, en el ordenamiento jurídico colombiano se encuentra que dentro del marco de los principios rectores de la materia, esto es, la libertad de empresa y su función social, existe amplia normativa que regula el comportamiento general de la empresa, pero frente al tema puntual o específico de la RSE, su control y mecanismos para exigirla resulta escasa.

A diferencia de lo que ocurre en el campo de regulación general de acción de la empresa, en el que existen numerosas normas que imponen obligaciones a las empresas desde diferentes áreas del derecho, en el ámbito específico de la RSE en Colombia únicamente se encuentra el establecimiento de incentivos tributarios a las compañías que realicen acciones sociales en determinados campos que reportan utilidad a la comunidad. Aun así, no se cuenta siquiera con mecanismos de control o parámetros claros que permitan hacer seguimiento a esto, imposibilitándose que dichas acciones cumplan con su real cometido y 
que cobre entonces pleno sentido el otorgamiento de beneficios.

Lo anterior pone de manifiesto que dentro del ordenamiento jurídico colombiano no se ha prestado especial atención a la regulación de la RSE, dejando el desarrollo de las acciones relativas a este tema en manos de las compañías. Se presenta entonces una clase de "autorregulación" que lleva a que muchas compañías obtengan injustificadamente ventajas derivadas del hecho de autodenominarse socialmente responsables, sin que la sociedad realmente obtenga los beneficios debidos. Este panorama reclama la intervención del Estado regulando los aspectos más importantes de la RSE, de modo tal que esta pueda hacerse exigible a las compañías y se obtenga la implementación de las acciones pertinentes y sus consecuentes ventajas.

Se propone entonces que el marco normativo general de acción de la empresa sea exigido a todas las compañías que funcionen en Colombia, regulándose así todos aquellos aspectos mínimos necesarios para que cumplan con sus funciones y objetivos esenciales de generación de riqueza y progreso, sin vulnerar o poner en riesgo otros derechos o bienes jurídicos en el desarrollo de sus acciones.

Ya en el escenario del cumplimiento de las obligaciones empresariales contempladas en el marco normativo general, se ofrecerá adicionalmente a la empresa la opción de ingresar al campo de la RSE, aspecto que estará a su vez regulado por parámetros que lo hagan efectivo. Dicha regulación contemplará las exigencias para el ingreso a este campo, las obligaciones que deberán cumplir

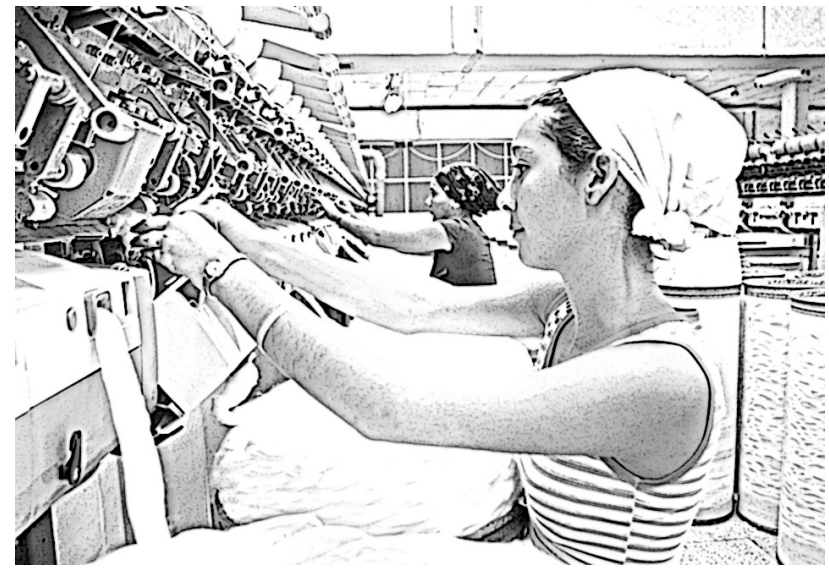

La empresa ocupa un destacado lugar en la sociedad en atención al importante rol que juega en la economía. Esto conlleva que deba prestarse mayor atención al ejercicio de sus actividades y a la forma como se relaciona con los sujetos frente a los cuales sus operaciones tienen incidencia. Con ocasión de lo anterior se han creado figuras que permiten establecer parámetros relativos a la forma en que se presenta dicha interacción, encontrándose la RSE entre las más importantes.

las compañías y las respectivas consecuencias que se derivarían de su incumplimiento. Existe así la posibilidad de que las empresas decidan voluntariamente si desean acogerse a dicha normativa, en atención a los incentivos que sean ofrecidos por el Gobierno o a los móviles propios que la puedan llevar a tomar dicha decisión.

Así las cosas, el legislador colombiano debe entrar a regular adecuadamente la materia a efectos de poder obtener de ella el mayor provecho. En tal 
sentido, deberá abarcar diferentes aspectos tales como el fomento y la divulgación de la RSE, la delimitación clara de los requisitos para ingresar o permanecer en este compromiso social, la creación o designación de las autoridades que ejerzan supervisión permanente sobre los programas de RSE y el otorgamiento de facultades necesarias para sancionar los incumplimientos e infracciones que se presenten en este campo. Adicionalmente, el Estado deberá brindar asesoría y acompañamiento constante, que les permita a las empresas cumplir a satisfacción con las metas y propósitos al respecto.

Esta propuesta, con plena sujeción a los principios de orden constitucional que rigen la materia, conlleva una mejora de las actuales condiciones de la

comunidad en campos como el medioambiental, de derechos humanos, laboral, entre otros, al generar beneficios para todos los sujetos involucrados y para la sociedad en su conjunto. Así, la cooperación del sector privado — que cuenta con medios y recursos para ayudar a satisfacer necesidades de la población - con el Estado - quien deberá intervenir en la materia a través de regulación adecuada - , permitirá garantizar derechos de la sociedad y mejorar considerablemente sus condiciones, gracias al trabajo mancomunado tanto de estos dos agentes como de la sociedad civil.

Vale la pena, entonces, darle una oportunidad a la RSE para que pueda convertirse en la respuesta a diferentes problemáticas sociales y ambientales que se presentan en la actualidad, siempre que el Estado la regule en forma debida, estableciendo con total claridad el tratamiento que esta deberá recibir en cada uno de los puntos expuestos a lo largo del presente artículo.

\section{Referencias}

Acevedo, J., Zárate, R. y Garzón, W. (2013). Estatus jurídico de la responsabilidad social empresarial (RSE) en Colombia. Díkaion 22(2), 303-332. Recuperado de: http://www.redalyc. org $/$ articulo.oa?id=72031061006

Alanis, L. Tello, M. y Sánchez, L. (2013). La responsabilidad social empresarial. Global Conference on Business and Finance Proceedings, $8(2)$. Recuperado de: http://rse2.wikispaces. com/file/view/o10-LA+RESPONSABILIDAD + SOCIAL+EMPRESARIAL.pdf

Arroyo, J. (2012). Promover al promotor: el Estado ante la responsabilidad social empresarial. Centrum Católica's Working Paper Series, 09(0004), 1-17. Recuperado de: http://centrum.pucp.edu.pe/pdf/working_paper_series/CERES_WP2012-09-0004.pdf

Carrillo, R. J. y Toca, T. C. (2014). Léxico para la responsabilidad social empresarial. Bogotá, Colombia: El Globo.

Cecil, L. (2008). Corporate Social Responsibility Reporting in the United States. McNair Scholars Research Journal, 1(6), 1-10. Recuperado de: http://commons.emich.edu/cgi/viewcontent.cgi? article $=1006 \&$ contex $\mathrm{t}=$ mcnair

Céspedes, B. L. y Gutiérrez, A. M. (2012). La responsabilidad civil por actividades peligrosas: una forma de establecer nexo entre personas jurídicas privadas y violaciones de derechos humanos en Colombia. Universitas, 61(125), 149-186. Recuperado de: http:// www.scielo.org.co/scielo.php? script $=$ sci arttext\&pid=S0041-90602012000200006\&ln $\mathrm{g}=\mathrm{es} \& \mathrm{nrm}=\mathrm{is} \& \ln \mathrm{ln}=\mathrm{es}$ 
Cittá del Vaticano. (30 Ianuarii 1971). Acta Aportólicae Sedis (AAS) 63.

Cittá del Vaticano. (7 Ianuarii 1991). Acta Apostolicae Sedis - AAS 83.

Comisión de las Comunidades Europeas. (2001). Libro verde. Fomentar un marco europeo para la responsabilidad social de las empresas (18.7.2001, COM 366 final). Recuperado de EUR-Lex: http:/ / eur-lex.europa.eu/legal-content/ES/ TXT/?uri=CELEX:52001DC0366

Consejo Empresarial Colombiano para el Desarrollo Sostenible [Cecodes). (s. f.). Responsabilidad social empresarial. Recuperado de: http://www.cecodes.org.co/index.php/ beneficios/responsabilidad-social.html

Correa, H. M. (2008). Libertad de empresa en el Estado social de derecho. Bogotá, Colombia: Editorial Externado de Colombia.

Crane, A., McWilliams, A., Matten, D., Moon, J. y Siegel, D. (Eds.). (2009). The Oxford Handbook of Corporate Social Responsibility. New York, United States: Oxford University Press.

Crespo, R. F. (2010). Entre el concepto y la práctica: responsabilidad social empresarial. Estudios Gerenciales - ICESI, 26(117), 119-129. Recuperado de: http://www.scielo.org.co/ pdf/eg/v26n117/v26n117a07.pdf

European Commission for Corporate Justice. (2006). Corporate Social Responsibility at EU Level. Proposals and recommendations to the European Commission and the European Parliament, 1-10. Recuperado de: http://www.europarl.europa.eu/meetdocs/2004_2009/documents/dv/eccadvocacybriefing 1 12006_/ eccadvocacybriefing 1 12006_en.pdf

Gayo, S. (2012). Mandatory and Voluntary Corporate Social Responsibility Policy De- bates in Indonesia. ICIRD, 1-5. Recuperado de: http://www.researchgate.net/publication/252508791_Mandatory_and_Voluntary_Corporate_Social_Responsibility_Policy_Debates_in_Indonesia

Gjølberg, M. (2009). ¿Cuantificando lo incuantificable? Creación de un índice de prácticas de RSE y rendimiento de la RSE en 20 países. Revista de Responsabilidad Social de la Empresa, II, 18-19. Recuperado de: http://www. luisvivesces.org/upload/58/92/RRSE2o9-completa_terceras.pdf

González, R. y Mayz, C. (2008). Responsabilidad social empresarial: ¿ibligación o potestad? Debates IESA, 13(1), 34-37. Recuperado de: http://virtual.iesa.edu.ve/servicios/ wordpress $/$ ?p=2224

Ibarra, P. A. (2014). Principios de la responsabilidad social empresarial en el ordenamiento jurídico colombiano. Revista de Derecho, (41), 52-82. Recuperado de: http://rcientificas. uninorte.edu.co/index.php/derecho/article/ viewArticle/ 5443

Ioannis, I. y Serafeim, G. (2014). The consequences of Mandatory Corporate Sustainability Reporting: Evidence from Four Countries. Harvard Business School, 1-35. Recuperado de: http://www.hbs.edu/faculty/Publication\%20 Files/11-100_7f383b79-8dad-462d-90df324e298acb49.pdf

Instituto Colombiano de Normas Técnicas [Icontec]. (2008). Guía técnica colombiana 180 de responsabilidad social. Bogotá: Autor.

Jaramillo, J. I. (2015). Derecho del trabajo en el postfordismo. El proyecto de regulación universal en la globalización económica. Bogotá, Colombia: Editorial Universidad del Rosario. 
Kordant Philanthropy Advisors. (2013). The 2\% CSR Clause: New Requirements for Companies in India. Kordant Report Series, 1-4. Recuperado de: http://www.kordant.com/ assets/2-Percent-India-CSR-Report.pdf

Kovaliov, R. y Streimiiene, D. (2008). The role of public sector in Corporate Social Responsibility Development in Lithuania. Economics and management, 55-67. Recuperado de: http:// www.zurnalai.vu.lt/ekonomika/article/viewFile/1055/544

Martínez, A. N. (2010). Buen gobierno y responsabilidad social empresarial, prácticas que favorecen los intangibles de la empresa. Capítulos de memoria II Congreso Internacional de Derecho Empresarial y Contractual.

Melo, J. O. y Guerra, M. J. (2005). Una propuesta para la regulación de la responsabilidad social empresarial del sector privado en Colombia. Bogotá: Pontificia Universidad Javeriana, Facultad de Ciencias Jurídicas. Recuperado de: http:// www.javeriana.edu.co/biblos/tesis/derecho/ dere7/DEFINITIVA/TESIS\%2010.pdf

Matten D. y Moon, J. (2008). "Implicit" and "explicit" CSR: A conceptual framework for a comparative understanding of corporate social responsibility. Academy of Management Review, 33(2), 404-424. Recuperado de: http://carleton.ca/ces/wp-content/uploads/ MattenMoon-in-AMR-2008.pdf

Naciones Unidas. (1999). Pacto Mundial. Recuperado de: http://www.un.org/spanish/ milenio/ares552.pdf.

Naciones Unidas. Asamblea General. (2000). Declaración del Milenio.
Narváez, J. I., Narváez, J. E. y Narváez, O. S. (2008). Derecho de la empresa. Bogotá: Colombia: Legis.

Núñez, C. M. (Abril, 201 1). La emergencia del discurso de la responsabilidad social empresarial (RSE) en el contexto del adelgazamiento del Estado. Alegatos, (77), 303-318. Recuperado de: http://www.azc.uam.mx/publicaciones/ alegatos/pdfs/70/77-13.pdf

Organización Internacional de Estandarización [ISO]. (2010). Norma ISO 26000. Guía sobre responsabilidad social. Ginebra: Autor.

Organización Internacional del Trabajo. (1977, 2000). Declaración tripartita sobre las empresas multinacionales y la política social. Ginebra: Autor.

Organización para la Cooperación y el Desarrollo Económico [OCDE]. (2011). Líneas Directrices de la OCDE para Empresas Multinacionales. Paris: OCDE Publishing. Recuperado de: http://www.oecd.org/daf/inv/mne/ MNEguidelinesESPANOL.pdf

Parlamento Europeo y Consejo Europeo. (2014). Directiva 2014/95/UE, por la cual se modifica la Directiva 2013/34/UE en lo que respecta a la divulgación de información no financiera e información sobre la diversidad por parte de determinadas grandes empresas (2014/95/UE). Recuperado del sitio de internet de la Unión Europea: http://eur-lex.europa.eu/legalcontent/ES/TXT/?uri=CELEX:32014LO095

S. S. Francisco. (2015). Carta Encíclica Laudatio Si. Sobre el cuidado de la casa común. Ciudad del Vaticano: Librería Editrice Vaticana. 
S. S. Pablo VI. (1971). Carta Apostólica Octogesima adveniens. Vaticano: Autor.

S. S. Juan Pablo II. (1991). Carta Encíclica Centesimus Annus. Vaticano: Autor.

Sabogal, L. F. (2005). Nociones generales de la libertad de empresa en Colombia.REVIST@eMercatoria, 4(1), 1-17. Recuperado de: https:/ / www.google.com.co/url? sa $=$ t\&rct $=\mathrm{j} \& q=\& e s$ $\mathrm{rc}=\mathrm{s} \& \operatorname{source}=\mathrm{web} \& \mathrm{~cd}=3 \& \mathrm{cad}=\mathrm{rja} \&$ uact $=$
8\&ved=0CDAQFjACahUKEwjcksfg_YbIA

hUGpB4KHencByU\&url=http $\% 3 \mathrm{~A} \% 2 \mathrm{~F} \% 2$

Fdialnet.unirioja.es\%2Fdescarga\%2Farticul o\%2F 3625833.pdf\&usg=AFQjCNFXrQD1Zor-8wAWGrkQAhgGTbTfw\&sig2=VzG oTBp9M4qPWaPYMipNMQ

Zavala, R. C. (1971). Derecho de la empresa. Buenos Aires, Argentina: Editorial Depalma. 